\section{Tebe boulstomian a dectures}

oN

\section{THE INFLUENCE OF PREGNANCY UPON CERTAIN MEDICAL DISEASES, AND OF CERTAIN MEDICAL DISEASES UPON PREGNANCY.}

Delivered before the Royal College of Physioians of London on Waroh 1'th, 19th, and 24th, 1908,

By HERBERT FRENCH, M.A., M.D. OxoN., F.R.C.P. LOND.,

ASSISTANT PHYSICIAN TO GUY'S HOSPITAI.

LECTURE II. ${ }^{1}$

Delivered on March 19th.

OTher Suppurative Renal AFFections in ReLation to Pregnancy. -Tuberculous and Caldulous DISEASES.

Mr. President aND GENTLEMEN,-The pyelonephritis which pregnancy itself gives rise to having been discussed, there remain two other suppurative renal affections to be mentioned. These are the various degrees of kidney mischief that may be due to stone and to tuberculosis respectively. There is little evidence to show that pregnancy is itself liable to give rise to either of these, and in the case of a tuberculous kidney the patient is, as a rule, so invalided that pregnancy is but rarely to be found associated with it. There has been no case of pregnancy coincident with tuberculous kidney in Guy's Hospital in the last 20 years. With renal calculus, on the other hand, the symptoms may be in abeyance for longer or shorter periods and the patient is not necessarily such an invalid that pregnancy may not occur. The question wil then arise as to what the effect upon the kidney is likely to be in such a case. It is clear that if a previously healthy woman may develop pyelonephritis during pregnancy, as described in the previous lecture, a woman who already has a lesion which also predisposes to pyuria must be in a position of increased danger when pregnancy occurs. On the other hand, the degree to which the kidney, or kidneys, may be already damaged by the calculi is so extremely variable that it is almost impossible to say what is going to happen when such a case comes under observation. If the calculus is a small one confined to the renal pelvis, the general substance of the kidney being but little affected, it is quite possible for the pregnancy to run its course without any trouble arising from it at all. If the stones are confined to one kidney and have led to its conversion into a hydronephrotic bag the other kidney may have hypertrophied by way of compensation, and the effect of pregnancy will be similar to that in cases where, after operation, only one kidney is left-a point to be mentioned again below.

Colic and hrematuria may occur in either of these cases, just as they may in non-pregnant persons. Treatment should then be directed to the renal condition, and the probability is that the untoward symptoms will subside and that the pregnancy will run its natural course, as was the case in six out of seven patients in the hospital. On the other hand, a patient with a renal calculus that is already causing suppurative inflammation of the kidney is bound to be a source of grave anxiety to her medical attendant should she become pregnant, especially from the fifth month onwards, that is to say during the time when there is particular liability for the pregnancy itself to cause pyelonephritis. It is doubtless possible by keeping the patient at rest, by preventing constipation or diarrhcea, and by administering anti-pyuric remedies, to enable her to reach her full term of pregnancy ; but there are cases in which the suppuration in the kidney will become worse, and the question will arise as to whether or not obstetric measures for terminating the pregnancy should be advised. One of the seven cases alluded to above proved fatal; it may probably be regarded as one in which pregnancy was the main cause of death by leading to a pyelonephritis upon the top of calculous disease. The following are brief details of the case :-

The patient was a young woman who had had pain in her right loin which in view of the subsequent events was doubtless due to a calculus.

1 Lecture I. was published in The LaNCET of May 2nd, 1908, p. 1257. No. 4419 .
She was otherwise in excellent health. She married and remained well until she was five and a half months pregnant. She then began to suffer from aching pains across her loins and from repeated vomiting. There was no odema but the urine was found to contain 5 parts per 1000 of albumin, with a fair number of renal tube casts, red corpuscles, and a considerable excess of leucocytes. Day by day the leucocytes in the mus, and the quantity of pus rapidly increased until there was no doubt about there being a progressive suppurative nephritis. No tr per cent but wo 17 per cent., but the patient became steadily worse, vomiling on the slightest exertion and after all food. There was no pyrexia such as there nearly always is in cases of ordinary pyelonephritis of pregnancy and there were no rigors. The bladder became infected by acute crstitis and the question of recommending obstetric measures for emptying the uterus had arisen, when spontaneous delivery of a living female child occurred at the seventh month. The patient's general condition improved for three days afterwards, though no day passed without the occurrence of vomiting. The latter then increased in severity; drowsiness with muttering delirium and hallucinations set in, with incontinence of urine; and on the fifth day after labour the patient became comatose and died without convulsions.

At the necropsy the only abnormal organs were the kidneys and the bladder. The uterus was perfectly healthy. Both kidneys were in a state of pyonephrosis, with secondary suppurative pyelonephritis, and in the pelvis of each there were numerous irregular calculi of oxalate of lime coated with white phosphates. The ureters were but slightly dilated. The bladder was in a condition of acute cystitis without ulceration.

Apparently the sequence of events had been : renal calculi, hydronephroses, pregnancy, microbial infection of the kidneys, pyonephroses, suppurative pyelonephritis, cystitis, uræmia, death. Unfortunately no exhaustive bacteriological examinations of the urine were made. One would not be surprised, in view of what has been already said in connexion with the pyelonephritis of pregnancy, if the micro-organism had been the bacillus coli communis in pure culture. This is a point for investigation in future cases.

\section{Non-Suppurative Renal Affections in Relation} to Pregnancy.

We may now pass on to consider the non-suppurative lesions of the kidney in their relation to pregnancy, and although these constitute a very big subject, and one which might easily occupy many lectures, it will be best to touch only upon a few points of it here because there is already a great deal of literature upon the matter, much of which is easily accessible to all.

There is still a good deal of discrepancy in the views held by different observers as to the nature of the lesions in question, for whereas some pathologists describe them as inflammatory others insist that they are not so but are rather acute toxic degenerations of the renal cells.

Clinical groups.-Clinically'there are three quite distinct groups of cases which some would distinguish from one another in kind as well as in type. 1. The cases in which renal mischief of the nature of Bright's disease has been known to exist previously to pregnancy. 2. The cases in which, previously to pregnancy, the urine was perfectly healthy and no previous attack of Bright's disease had occurred; but in whom during pregnancy, and beginning, as a rule, at or before the middle of the pregnancy, puffiness of the ankles, back, and eyelids appears, the urine at the same time becoming less in quantity and containing albumin, renal tube casts, and possibly blood, in a way which closely simulates ordinary acute Bright's disease. For the sake of brevity these are referred to as the "cedema cases." 3. The cases in which the patient has seemed to be in perfect health until the later months of pregnancy, or even until immediately after labour, and then without much warning and usually with only slight evidences of cedema develops the well-known symptoms of puerperal eclampsia. It is not at all improbable that there is a fourth clinical variety of renal disease that has a relationship to pregnancy-namely, the granular contracted kidney. It is very difficult to prove or to disprove this, because even if a granular contracted kidney in a given case owes its inception to renal trouble arising during pregnancy the patient can still continue to live for many years without untoward symptoms, and by the time death occurs there will be nothing in the post-mortem examination to show either how long the renal mischief has been present or how this mischief first began.

Recurrent obstruction to ureters is a potent cause of renal fibrosis and it is conceivable that many successive preg. nancies may lead to sclerosis of the kidneys without there having been any of the symptoms of acute Bright's disease. I have accumulated some evidence to show that not only pregnancy but also pathological affections of the pelvic organs, such as prolapse of the uterns, may lead to fibrotic kidneys, with hypertrophy of the left ventricle of the heart and all the other changes that are usually associated with 
red granular kidney, even including cerebral hæmorrhage. The data, however, are not jet complete, so that it will be best to leave the red granular kidney out of the question now under discussion and to confine attention to the three different clinical types of renal disease mentioned above.

First in regard to pregnancy arising in a patient known to have Bright's disease at the time conception occurred. It is so clear that pregnancy is apt to have a deleterious effect upon the kidneys that it is manifestly unwise for a girl or woman with existing nephritis to get married. If the urine already contains both albumin and renal tube casts, there is a great risk that pregnancy will make the condition far worse and accelerate the end. The surprising thing is that some patients known to have persistent Bright's disease before pregnancy sometimes live to bear many children, even in spite of exacerbations of their renal symptoms during pregnancy. Such cases are exceptional, no doubt, but on going through the hospital records one finds several of this kind. In one there had been all the signs of chronic tubal nephritis for 13 years, the patient had been married for eight years, she had borne five children, and bore a sixth alive at term in the hospital. This was not a case of recurrent acute nephritis but of persistence of both albuminuria and tabe casts; it is the more remarkable in that, even without the additional strain of pregnancy, it is unvsual for a patient with such a renal condition to survive so long. Such an exceptional case merely shows that both pregnancy and survival may occur in a case of chronic Bright's disease; it does not follow that medical advice should not be against marriage in other cases of the kind.

There now remain the two groups of cases in which the renal disease is directly attributable to pregnancy-namely, those who develop renal cedema in the middle months and those who develop eclampsia at the end. The fact that these two forms of renal disease are really attributable to the pregnancy is so well established that it needs no discussion. In the majority of the cases both albumin and renal tube casts disappear from the urine in a remarkable way when the pregnancy has terminated. Clinically, the two types are so different that many authorities regard them as absolutely distinct renal affections; and some hold that both these two forms, besides differing from one another, are also entirely different from those renal affections which arise from other causes and which are usually grouped together under the title acute or subacute Bright's disease. It is very probable that the question of whether these pregnancy kidneys are really forms of Bright's disease or not will remain a matter upon which there will always be differences of opinion. The extent to which opinions differ at present is well exemplified in Sir T. Olifford Allbutt's "System of Medicine," where the accounts given in different volumes by such authorities as Dr. G. K. Herman and Dr. W. Howship Dickinson respectively, are remarkably at variance. Speaking of the morbid anatomy and histology of the kidneys in the two types of disease under discussion, Dr. Herman says of the first-namely, that in which odema of ankles and eyelids in the earlier months is the main symptom-which he calls the "chronic renal disease of pregnancy ":-

We know nothing of the morbid anatomy of this chronic disease, for it is not fatal. The morbid changes in the kidney can only be found out by examining the kidneys of a pregnant woman who, having the disease, died from some accidental cause, and I know of no such
record. A few necropsies have been published, but the accounts are record. A few necropsies have been published, but the accounts are
not harmonious, for the evident reason that the patients who died were suffering from forms of renal disease such as occur independently of pregnancy and not from that which depends upon pregnancy.

This does not seem to be altogether fair, for it is as much as to say: "The chronic renal disease of pregnancy is different from that of chronic tubal nephritis due to other causes; therefore, if at a necropsy made upon a patient dying pregnant, or recently pregnant, lesions resembling cbronic tubal nephritie are found, the nephritis is not that which pregnancy causes." It appears to be an argument in a circle in which the conclusion that is drawn is also one of the premisses of the syllogism.

Dr. Howship Dickinson, on the other hand, writes very differently. He says :-

The changes which occur in the kidney as consequences of pregnancy may be briefly indicated. They are the changes of heart disease and something more. To passive congestion is superadded an acute inflammation. In an early stage there is much hypercmia, with obvious case destined to further trouble, a somewhat peculiar form of diffuse nephritis succeeds ; the tubes become loaded with epithelium which early takes on fatty chance and imparts a yellowish colour in streaks or otherwise, to the section. The fatty change is not limited to the epithelium, but may be somewhat general. The tubal change is accom. panied or quickly followed by interstitial contractile growth, with consequent compression of the tubes, particularly near the surface, and superficial granulation. The condition is one of general nephritis, upon which granular contraction ensues with inordinate rapidity. So early does the contractile process become superadded to, or intermixed with that of inflammatory swelling that the more bulky results of renal nflammation are excluded; the large white kidney does not, under these circumstances, present itself. The early access of inflammatory chang would seem to imply that other causes are at work beside the mechanical, and that these are analogous to those to which other forms of nephritis have been traced. It has been suggested that the kidneys are irritated by some product of pregnancy, possibly an excrementitious result of foetal nutrition. The conjunction of the two morbid agencies, the mechanical and the vital, may account for the greater activity of the disease as compared with the granular kidney of diffuse nephritis, upon which granular contraction is rapidly superimposed.

Referring now to the kidneys found at necropsies in cases of fatal puerperal eclampsia, Dr. Herman says :-

Very different conditions of kidney have been found. A comparison of the different accounts that have been published shows that they may be divided into three groups. First, disease of the kidney such as may occur apart from pregnancy, ...... such as lardaceous disease, hydronephrosis, or dilatation of the ureters and renal pelves. Secondly, in most cases there are changes in the kidneys which to the naked eye resemble those of acute or chronic tubular nephritis. Thirdly, in some cases the kidneys have shown no sign of disease appreciable by the un. aided senses. When these kidneys, either those looking like kidnoys with acute and chronic nephritis, or those which look healthy, are with acute and chronic nephritis, or those which look healthy, are examined with the microscope, the changes are not those of inflam

These changes have been variously described by various authors, the following being some of the descriptions. Pro. fessor Hamilton says :-

Judging from the naked-eye appearances we expected that parenchy. matous inflammation of the tubular epithelium in the cortex, passing into a state of fatty degeneration, would be revealed. The first glance at a section of the organ, however, showed conclusively that this was not the case and that the lesion was not an ordinary parenchymatous inflammation. It consisted of degeneration of the epithelial cells of a certain proportion of the tubules in the circumferential aspect of the cortex. The degeneration appeared to be of a colloid nature. The products of these degenerated cells ran down and blocked up, more or less completely, the other convoluted and straight tubules, so as to render them functionally useless, although their tissues were not diseased.

Dr. Charlewood Turner, in a case of Dr. Herman's own, says that the sections-

show recent degenerative changes of the cortex, without any oider or cirrhotic lesions, changes attributable to some toxic matter in the blood. Granular degeneration and swelling of the epithelium of the convoluted tubes, the nuclei of which are invisible, and swelling of the connective tissue throughout, without infiltration of lencocytes. In the medullary tissue the epithelium of the loops and connecting tubes appears normal. Some of the lonps contain casts. There is much vascular congestion in this part. The glomeruli appear normal. There is no exudation in the capsules.

Dr. W. J. Fenton, reporting upon a case, says :-

Most tubules show what is apparently a running together of the cells, having no definite structure, and having their nuclei obscured, the having no definite structure, and having their nuclei obscured, the
whole condition of the epithelium being similar to that often found in whole condition of the

\section{And so on-Dr. Herman's conclusion being that-}

From these different observations, made by independent pathologists having no hypothesis to support, it follows that, although the kidneys often look like inflamed kidneys, yet that the lesion of puerpera by blood poisons.

It would serve no useful purpose to give all the multitudinous literature of the subject here. The above quotations sufficiently show that the greatest authorities are in complete opposition as to the nature of the renal changes in the kidney diseases to which pregnancy gives rise. One says that they are not nephritic at all; another that they are nephritic, and nephritic in remarkable degree. The matter must remain largely one of opinion.

The crux of the whole question is: What is nephritis? and What are its different kinds? and even to these questions no absolute answer can be given. The varieties of nonsuppurative affections of the kidney included under the heading "Bright's disease" run so much into one another and so much confusion has arisen from attempts to keep up a distinction between tubal and interstitial nephritis that it is not to be wondered at that that which some authorities would term a nephritis is refused that title by others.

Dealing with the question from another point view, it will probably be granted that the kidney lesions which occur during and immediately after scarlet fever are those nephritis. Whether or not the fibrotic changes which may occur in kidneys which have been inflamed during scarlet fever are also inflammatory is doubtful. It is probably incorrect to speak of chronic nephritis in many instances, for 
that which is usually referred to as such is the fibrosis which results from former acute or subacute inflammation, the inflammation itself having ceased long since. A similar misapplication is frequent in regard to valvular heart disease: valves which are crippled as the result of former endocarditis are often spoken of as being the site of chronic endocarditis, when what is really meant is fibrosis from former endocarditis, all actual inflammation being now past. Scarlet fever may cause nephritis which, instead of either resolving completely or leading comparatively soon to a fatal result, may leave behind it a fibrosis. It is not this lesion which is at present under discussion but the acute or subacute lesions which are on all hands allowed the title scarlatinal nephritis.

The kidney which may be found post mortem in such cases is very variable in its naked-eye appearances. Sometimes it is a large red blood-dripping organ, without much blurring of the structural outlines; sometimes it is a large pale kidney, with lack of clear definition between cortex and medulla; more often it is a combination of these two types, a large organ variously mottled with pallid and with crimson streaks and blotches, the general effect being in the direction of redness in some, in the -direction of pallor in others, whilst sometimes there is about an equal proportion of redness and of pallor in the mottling. Granted time between the onset of the inflammation and the time of the patient's death, a variable degree of contraction of the kidney will have resulted, with unevenness of the surface owing to irregularity in the distribution of the fibrosis, the colonr varying here again between pallor on the one hand and redness on the other as much as it does in the large kidneys of the earlier stages of the disease.

The microscopical changes are equally variable. Confining attention mainly to the acuter stages, the most striking feature is the obstruction and distension of the tubes, which are stuffed with epithelium, granular débris of cells, and often blood and fibrin, to the more or less obliteration of their channels. Sometimes the fibrin is so abundant as to occupy most of the tubes to the exclusion of their epithelial lining. Often the epithelinm of whole groups of tubules seems to have undergone a sort of coagulation necrosis, the line of demarcation between each cell and its neighbour being no longer visible, and the nuclei no longer taking the ordinary stains. In the more protracted cases the peri-glomerular and inter-tubular connective tissue shares in the inflammatory process, displaying hypernucleation and proliferation of the connective tissue cells. The degree to which small round-celled infiltration occurs is extremely variable. Sometimes it is almost entirely absent, sometimes it is very obvious, particularly around the glomeruli and in the cortex. The patient may not die until, although there is still actual inflammation present in some places, in others there has been time for fibrosis to have occurred. In short, both the macroscopic and the microscopic appearances of kidneys that are the seat of scarlatinal nephritis are extremely variable, though it can scarcely be said that the different appearances constitute intrinsically different kinds in the inflammation. If any broad rule can be laid down it would be that the sooner after the onset the patient dies the more will the appearances be those of a coagulation necrosis of the epithelium ; the longer the patient lives, supposing always that the renal mischief does not entirely resolve, the more will be the connective tissue change, first that of hypernucleation, and finally that of fibrosis.

If the description that has been given of the acute and subacute changes in the non-suppurative renal diseases of pregnancy be now recalled, it will be found that these are extremely similar to those that occur in connexion with scarlet fever. If the scarlatinal changes are to be termed nephritis then those associated with pregnancy are surely nephritis too. There have been in Gay's Hospital of recent years four fatal cases of the cedema type and 15 fatal cases of the eclamptic type of renal trouble in pregnancy ont of a total of 71 cases of the former and 51 cases of the latter. There is little need to recount the changes that were found at the necropsies, because there is little to add to the descriptions already given above. If the kidneys themselves or microscopical sections of them had been mixed up amongst a large number of different scarlatinal nephritis kidneys and their sections, it would have been next to impossible to have gone through them and sorted the pregnancy kidneys from the scarlatinal. Large red, large mottled, large pale, contracting red, contracting mottled, and contracting pale kidneys were all represented, with a predominance of the large mottled and large pale kidneys in the eclampsia cases and of the contracting kidneys in the cedema cases. There were great variations in the microscopical appearances in different cases also. Sometimes cloudy swelling or coagulation necrosis of the epithelial cells in the cortex was the main thing; sometimes even in the eclampsia cases there was hypernucleation of the connective tissue as well. In the odema cases there was a variable degree of fibrosis, mature and immature, which occasionally reached an extreme degree even in kidneys that were not very obviously contracted. It would seem that every kind of change which may be found in scarlatinal nephritis may also be found in these kidney affections of pregnancy. I therefore range myself with those who regard these kidney changes in pregnancy as essentially similar in kind to those which may occur in scarlet fever, and I believe that there is no intrinsic difference, but only one of degree and aouteness, between the renal changes in eclampsia cases and those in cases where renal œdema is a prominent symptom less late in the pregnancy.

\section{The Cause of Pregnanoy Nephritis.}

It is not possible to say precisely what is the cause of the nephritis in pregnancy. It is generally believed to be a toxin - that is to say, a poison of unknown nature-elaborated during pregnancy. To term the changes in these pregnancy kidneys "toxic" does not imply that they are intrinsically different from those of scarlatinal nephritis, where the precise cause, being equally unknown, is termed toxic too. There are doubtless many different substances which can canse similar inflammatory lesions in the kidneys. Pneumococci have been recovered from these organs in cases of acute non-suppurative nephritis associated with lobar pneumonia. Streptococci have been recovered in a similar way from some scarlatinal nephritic kidneys. Cantharides, turpentine, and oxalic acid can cause very similar renal changes. It is more than likely that in certain cases pregnancy gives rise to a poison of some kind which in turn is the cause of the nephritis.

Nothing is really known as to why in some cases eclampsia should be the prominent feature, whilst in others odema is marked and eclampsia absent, and whilst in yet others both occur. The parallel with scarlet fever nephritis still holds good in this respect, however. There are cases of scarlatinal nephritis in which œdema in entirely absent, and uræmic symptoms are the first to attract attention; whilst there are other cases in which cedema is a marked feature without uræmia. There is an admirable paper upon the subject by Dr. F. M. Turner. ${ }^{2}$

Notwithstanding all the work that has been done upon uræmia its pathology is still unknown. of late years attention has been directed less exclusively to the kidneys in the study of the subject, and there is some evidence to show that the liver as well as the kidneys may play an important part in the origin of uræmic or eclamptic symptoms. The liver is nearly always abnormal in these cases, the chief changes being cloudy swelling, fatty change, and acute necrosis of the hepatic cells. It would not be surprising if the liver condition had something to do with uræmia, seeing that, if jaundice were deducted from the later symptoms of acute yellow atrophy of the liver, the clinical picture of the latter would not be very unlike that of uræmia.

Before leaving the question of whether or not the renal lesion of eclampsia is really similar in kind to the renal lesion of the cases where general cedema is the main symptom, it may be of interest to note that four out of the 71 cases who were admitted for the cedema type of nephritis in association with pregnancy had suffered from typical acute eclampsia in a former pregnancy. Eclampsia is not so common that this can be a mere coincidence. If the same patient is liable to acute eclampsia in one pregnancy and then to the cedematous form of nephritis without eclampsia in a later one, it is very suggestive of there being a relationship in kind between these two clinical forms of renal disease. If these were cases in which the odema type of nephritis had come first and then eclampsia in a later pregnancy the argument would not be so good, though there are cases of this kind too. The four cases referred to had never had symptoms of nephritis apart from pregnancy; their first symptoms of renal tronble were those of puerperal eclampsia towards the end of their first pregnancy. Recovery from this appeared to be complete, and in a subsequent pregnancy there was the nephritic type of oedema associated 
with albumin and renal tube casts in the urine and without eclampsia. The renal symptoms and urinary abnormalities again resolved after the later child was born.

It would be interesting to trace the after-histories of all the cases of eclampsia that have recovered for the time being and note what happened later. The writer has tried to do this with hospital patients, but the number of cases lost sight of is so great that the statistics obtained so far are too small to be of value. This would be a subject very suitable for a collective inquiry. The cases that have been traced show that puerperal eclampsia has recurred in some without necessarily proving fatal; that in others, as has been mentioned, renal cedema without eclampsia has taken its place in a subsequent pregnancy; whilst others, again, having recovered from eclampsia, have borne subsequent children without either œdema, albuminuria, or eclampsia. It is not improbable that the same would be true of scarlatinal nephritis if scarlet fever could recur in the same patient as often as pregnancy can.

Returning now to a consideration of all the cases together, they are found to bear out entirely what has been noted by others in regard to: the relatively better prognosis in the œdema type of pregnancy nephritis as compared with the eclamptic; the high proportion of primiparæ amongst the eclampsia cases and the preponderance of multiparæ amongst those who develop the odema type of nephritis ; the relatively high percentage of cases in which albuminuric retinitis occurs; the relatively greater severity of the symptoms when the uterus contains twins; and the liability for the children to be born prematurely or dead, or for them to die soon after birth.

The immediate maternal mortality.-Out of 71 patients with renal odema and no eclampsia four died whilst in hospital, an immediate maternal mortality of 5 per cent., whereas out of 51 cases of puerperal eclampsia 15 died, an immediate maternal mortality of 29 per cent. This is a relatively small mortality as compared with that of acute uræmia not associated with pregnancy.

The number of previous pregnancies.-Of the puerperal eclampsia cases 76 per cent. of the patients were primiparæ; of the remainder most had had only one previous child, but in two cases there had been 10 and 12 previous pregnancieg respectively. Of the cases with renal odema and no eclampsia, on the other hand, only 36 per cent. were primiparæ, 64 per cent. having borne a former child or children, whilst a considerable number of the multiparæ had had from four to 12 pregnancies without evidence of nephritis before. Leaving the eclampsia cases aside, as being of less interest to physicians, it is found on analysing the 71 cases in which there was renal odema without eclampsia that 70 per cent. had never had symptoms of renal disease until the time when they developed during the pregnancy; that 10 per cent. had passed through a former pregnancy without symptoms of nephritis, but subsequently developed them when not pregnant, and suffered from an increase in the symptoms during a later pregnancy; that 7 per cent. had had acute nephritis before they were married and suffered from recrudescence of that trouble during pregnancy; that 6 per cent. had had eclampsia with a former pregnancy and now had symptoms of ordinary nephritis during pregnancy; that 6 per cent. had had symptoms of nephritis during a former pregnancy, recovering between whiles, but exhibiting the nephritic symptoms again when subsequently pregnant (in one of these cases nephritis with oedema, but without eclampsia, had recurred with each of four successive pregnancies); and that 1 per cent. had had no symptoms of nephritis during pregnancy and had had no eclampsia, but developed the symptoms of acute nephritis, with general œdema, during the puerperium.

As regards the month of pregnancy at which the renal trouble became manifest, that of eclampsia was, as all observers agree, in the latest months or immediately following labour; whereas in the cases where renal cedema was the main symptom the onset was at any time between the second and the eighth month, the trouble manifesting itself about the fifth or sixth month in the majority of cases. In this connexion it might be asked: If a pregnant woman develops evident cdema of renal type, with albumin and tube casts in the urine, during the eighth month of pregnancy, what is the likelihood that she will also have eclampsia? It would require a larger number of cases than the above for any absolute answer to be given to this question. It is fairly clear that if nephritis with cedema develops in the early or middle months of pregnancy it is quite exceptional for eclampsia to occur when the pregnancy is more advanced. It is also quite clear that the majority of cases of eclampsia have little or no cedema. Thus in 49 per cent. of the eclampsia cases there was no cedema at all ; in 35 per cent. there was definite though slight cedema of the face and ankles; in but eight cases, or 16 per cent., the general œdema was extensive, though it only developed in the later months.

Amongst the renal cases in which no eclampsia occurred there were nine in whom generalised cedema developed for the first time during the eighth month or later. There were thus 17 cases in whom extensive renal cdema first appeared in the eighth month, eight of them subsequently developing eclampsia and nine of them not doing so. It seems therefore that a broad answer to the question propounded above is, that when renal cedema first develops as late as the eighth month of pregnancy, the chances as to whether the patient will suffer from eclampsia or not are about equal.

$$
\text { Albuminuric Retinitis. }
$$

It is generally allowed that albuminuric retinitis in these pregnancy kidney cases is more common than it is in other forms of nephritis. The above cases conform with the general conclusions arrived at by others. Unfortunately, there was not an ophthalmoscopic record kept in every instance. Of the 71 cases without eclampsia 13 had albuminuric retinitis, two dying; $10 \mathrm{had}$ no albuminuric retinitis, none dying; and in 48 cases the condition of the eyes is not noted. Even if it be assumed that there was no albuminuric retinitis in all of these, which is improbable, the incidence of the retinal changes is nearly 20 per cent.; whereas in 312 consecutive cases of chronic nephritis not associated with pregnancy the incidence of the retinitis was 11 per cent.14 per cent. in those diagnosed as chronic tubal and 9 per cent. in those thought to be chronic interstitial nephritis.

It is generally acknowledged: that albuminuric retinitis is less likely to occur in acute Bright's disease than it is in chronic; nevertheless, it was well marked in 3 of the eclampsia cases, 2 of them dying. It was absent in 9, of whom none died; and there is no mention of the retinx in the remainder.

Amaurosis was present in several cases in which the optic discs and retinæ were normal.

It has been said that pregnancy cases with albuminuric retinitis have a less unfavourable prognosis than have others with a similar lesion. This is perhaps true to the exten that in a few instances the retinal mischief has been known to disappear again after the pregnancy is over. In at least one of the above cases in which albuminuric retinitis was well marked during pregnancy the albuminuria, the cedema, and the retinitis disappeared entirely after the child was born. Nevertheless, the presence of the retinal changes is a sign of extreme gravity even in the pregnancy cases, the immediate mortality amongst the 16 cases who had it being 25 per cent.-15 per cent. in the non-eclamptic cases and 66 per cent. in those who had eclampsia.

\section{The Effect of Iwins.}

The deleterious effect of twin pregnancy upon the kidneys is more marked in the eclampsia cases than it is in those with general cedema without eclampsia. Amongst the 71 cases of the latter there was not one of twin pregnancy, whereas amongst 51 of the former there were twins in 4 ; that is to say, in 8 per cent. The normal proportion of twin to single pregnancies is as 1 to 80 , so that the incidence of twin pregnancies in eclampsia cases is more than six times greater than the average. This is precisely what has also been quoted by Schauta, ${ }^{3}$ Hofmeier, ${ }^{4}$ Löhlein, ${ }^{5}$ Schreiber, ${ }^{6}$ and others, whose conjoint statistics show that in between 7 and 8 per cent. of eclampsia cases twins are present. This remarkable fact strongly supports the view that the nephritis is due to a toxin elaborated by the placenta or by the foetus, for, as Dr. Herman and others point out, the mere bulk of the uterus will not account for it. "Nothing like eclampsia is ever met with in cases of abdominal tumours-ovarian cysts, uterine fibroids, and so forth-which sometimes get much larger than any pregnant uterus. The frequency of eclampsia with twin pregnancy arises from the presence of two children in the womb and not from mechanical dis. tension of the abdomen."

3 Archiv für Gynäkologie, vol. xviii.

4 Zeitschrift fuir Geburtshinlfe und Gynäkologie, vol. vi.

6 Archiv fiir Gynäkologie, vol. li. 
The Effects of the Nephritis upon the Child.

Whether it is that the influence of the nephritis upon the foetus is bad or that the poor condition of the foetus is in some way the cause of the nephritis is a moot point. The fact, however, that some of the children are born healthy and live to grow up notwithstanding the renal trouble in the mother would seem to indicate that in the other cases the foetus suffers because the mother has nephritis rather than vioe versâ. All statistics show a high mortality amongst the children and those under discussion form no exception. Leaving the eclampsia cases out of account, the other type of patients show that in 18 per cent. of the cases the child was born too premature to live; in 23 per cent. the child was born near to, or at, term, but dead ; whilst in the remaining 59 per cent. the child was born alive, but in a number of instances with too little vitality to continue to live long.

Treatment.

It is not the province of these lectures to enter upon treatment at any length, so that but a few words will be said about it. Clearly the treatment of an eclamptic case lies mainly with the obstetrician. That of the nephritis of the earlier months of pregnancy, however, calls for immediate obstetric measures in but a few cases. Rest in bed, with medicinal, dietetic, and other measures precisely similar to those employed in other cases of acute or subacute nephritis, ameliorates the renal symptoms in many of the cases. The cedema and the albuminuria may thereby almost disappear before the end of pregnancy is reached. The average patient of this kind does better when treated upon the same lines as a non-pregnant case than if obstetric measures for the termination of the pregnancy are recommended and adopted. If, however, the renal mischief increases instead of diminishing, as is sometimes the case, notwithstanding all medicinal treatment-particularly when the latter has not been adopted and insisted upon at the very beginning of the trouble-the case will probably require the assistance of an obstetrician before term; although the relief to the nephritis after an artificial termination of the pregnancy is not as a rule so rapid as it is after natural delivery.

Pregnancy in Patients who have only One Kidney.

Seeing that so much stress has been laid upon the renal affections that pregnancy itself may cause it might well be asked whether a patient who for one reason or another has had one of her kidneys removed ought to be advised not to marry. It must be remembered that although pregnancy sometimes gives rise to nephritis or to pyelonephritis the total proportion of all cases in which it does so is exceedingly small. Moreover, it is well known that after excision of one kidney the other, if healthy, has a very remarkable power of hypertrophying by way of compensation. Such a single kidney is seen in the post-mortem room now and then and it may weigh nearly as much as two ordinary kidneys. It would be expected, therefore, that if there was no evidence of disease in the remaining kidney and if the patient was otherwise in good healtb pregnancy might be incurred without any untoward symptoms whatever. This is, in fact, what Mr. G. E. Twynam ${ }^{7}$ has found to be the case. It may be added that since the greater strain is put upon the right kidney daring pregnancy the case is more likely to do well if it is the left kidney that remains ; and further that since com. pensatory hypertrophy of the kidney must take some time to become complete a year or more should elapse between the nephrectomy and the occurrence of pregnancy in any given case. ${ }^{8}$

Tetany and Pregnancy.

Another condition of which pregnancy seems to be one of the causes is tetany. One of the most interesting points in regard to the association of pregnancy with tetany is perhaps its apparent rarity in London. There does not seem to have been a single case of the kind in Guy's Hospital during the last 30 years. The writer has not seen a case of the association, though he has seen several instances of tetany in adults, chiefly in conjunction with gastric lesions. Incidentally, as a point which possibly supports the toxic theory of 7 Brit. Med. Jour., Feb. 12th, 1898, p. 423-425, and West London
Medical Journal, 1898.

× See also Schramm: Berliner Klinische Wochenschrift. No. 6, 1896. Fritsch: Die Krankbeiten der Frauen, Berlin, 1894. p. 98. Israel Archiv fiur Klinische Chirurgie v. Langenbeck, vol. xlvii., 1894. Tridondani : Annali di Ostetrica e Ginecologia, July, 1896. C. E. Purslow: Brit. Med. Jour., 1698, Part I., p. 817. H. E. Maberly: Brit. Med. Jour., 1898, Part 1., 1. 604. A.Paunz: Verhandlungen des Königlichen Ungarischen Aerzterereins zu Budapest, Feb. 7tb, 1906, p. 11. the disease, it may be mentioned that more than one case excreted quantities of diacetic acid and acetone in the urine. It is well known that both these substances appear in the urines of many cases of gastric disorder quite apart from tetany and that they also appear in conditions of starvation, so that possibly the gastric disorders lead to acetonuria, partly or wholly as the result of semi-starration. Nevertheless, in an instance recorded by Dr. David Forsyth ${ }^{9}$ the paroxysms of tetany in a patient who also had evidence of gastric ulceration were always associated with an increased degree of acetonuria. It would be interesting to know whether diacetic acid and acetone were also present in the urine in cases of tetany associated with pregnancy or in those following operations upon the thyroid gland; and further, whether large doses of sodium bicarbonate had any beneficial effect upon the symptoms and course of the tetany, as might be the case by analogy with the treatment of acidosis in cases of diabetes mellitus.

That pregnancy and tetany are not at all generally related to one another as cause and effect is further shown by the comparatively small amount of literature there is upon the subject. One of the best-known monographs about it is that of Frankl-Hochwart. From this and from other papers one learns three particularly interesting points about the disease -namely, first, that in places where it occurs at all it bears a remarkable relationship to the time of vear; the great majority of the cases arise in the late winter and early spring. Out of 59 cases collected by Frankl-Hochwart ${ }^{10} 39$ occurred in January, February, March, or April, whilst only 13 occurred exclusively in the remaining eight months of the year. Secondly, that there is a noteworthy tendency for the disease to be almost epidemic. There is a little difficulty in interpreting some of the accounts, for the disease was undoubtedly diagnosed erroneously in years gone by. Epidemic cerebro-spinal meningitis was formerly confused with tetany, for example. Hysteria affecting many individuals of a township, analogous to that of the dancing Dervishes or to that of the chorea of the ancients, constitutes another difficulty. Even allowing for this, however, the records show clearly that in places where tetany occurs there are some years in which the cases are quite numerous and then others when the disease almost disappears from the neighbourhood. In Paris, for example, where the tetany of pregnancy used to be quite frequent, it is now said to be a condition of great rarity. Thirdly, in correspondence with the above it appears to be a disease of extremely local distribution. Very rare in London, and apparently throughout Great Britain, formerly common in Paris and now rare there, rare throughout America, the two places where it seems to be the reverse of rare are Heidelberg and Vienna. It appears to be endemic in these two cities. It by no means follows, of course, that it is microbial in origin. It is well known that such diseases as cirrhosis of the liver or acute gout, common though they are in some places, are quite rare in others, although there is not yet any proof that either of these is of bacterial origin. There is no reason to suppose that the tetany sometimes associated with pregnancy differs essentially from adult tetany due to other causes. There is no need to discuss its general symptoms here, for they are well known.

\section{The Pathology of Tetany.}

The pathology of the condition is obscure, though there is. much evidence to show that a toxin, and possibly not always the same toxin, is at work. The morbid lesions that have been described have chiefly been changes in the anterior cornual cells of the spinal cord and the corresponding cells in the medulla oblongata. Such changes would agree with the altered electrical reactions noted in the muscles during life. There is no complete reaction of degeneration, for excitability to the faradic current is retained; but with the galvanic current, instead of the kathodal closure contraction being more easily obtained than the anodal closure contraction, there is an altered polar response which may be summarised by saying that anodal closure contraction and anodal opening contraction are both obtained more readily than kathodal closure contraction. The changes in the spinal cord cells do not seem to be permanent, for the majority of the cases get perfectly well, though there is a tendency for the tetany to recur in zeveral different pregnancies, not necessarily successive, in the same person.

Guy's Hospital Gazette. 1902

10 Die Tetanie, Berlin, 1891. See also Dakin: "Tetany in Pregnancy," THE LANCET, May 16th, 1891, p. 1103, where all cases recorded up to that date are collected, with references. 
The other points that may be of interest are, briefly, the following. The patient usually escapes during the first half of pregnancy, the affection developing in the later months as a rule, though it occasionally shows itself earlier. The spasms are rarely met with during labour-a remarkable point, seeing that they are so readily produced by muscular efforts at other times. They may occur for the first time during lactation, though this seems to be less common than for them to arise during pregnancy and then continue during lactation. If they occur during lactation it is clearly impossible for the mother to suckle the child, for she is unable to hold it securely. It is necessary to feed the baby artificially, not only for its own sake, but also because it leads to the more rapid subsidence of the tetany in the mother. The treatment of the condition is similar to that of tetany in non-pregnant persons. Finally, the tetany in the mother seems to exert less ill-effect upon the fcetus than might be expected.

We may now leave the medical diseases, of which pregnancy is itself the exciting cause, and pass on to the discussion of other medical affections which, though not actually caused by the pregnancy, may yet arise or be already present in a pregnant woman. There is hardly a medical disease, from a common cold to a cancer, that may not be thus present and it is of essential importance to know in what respects, if any, the prognosis and the treatment in the case of a pregnant woman suffering from such intercurrent malady differ from the prognosis and the treatment in other cases. It is manifestly impossible to discuss every such disease in the time at our disposal; many must be left unmentioned.

Appendicitis in association with PREgnancy.

The question of appendicitis is always one of interest. What is the influence of pregnancy upon appendicitis and vice versá? This would be an excellent subject for a collective inquiry. The number of cases of pregnancy in association with appendicitis seen by a single individual is not likely to be great, and the cases that can be collected from the literature are almost necessarily those which are the more severe. The mild cases, which get better without anything very active being done, escape publication, and a collective inquiry which would cover all cases, whether mild or severe, would probably lead to conclusions that could not tout be helpful to all.

There is a certain amount of literature upon the subject, some of which has been collected by $\mathrm{Mr}$. George Heaton ${ }^{11}$ of Birmingham General Hospital. One of the chief difficultio in connexion with the matter is that of diagnosis. Inflammatory and other lesions of the right Fallopian tube or ovary may simulate appendicitis very closely. The ordinary vomiting of pregnancy may be regarded as the whole trouble when there is really appendicitis, whilst, on the other hand, when a special outlook is being kept for appendicitis the latter may be diagnosed when none exists. The difficulties that may arise when the lesion is really in the kidney-the pyeionephritis of pregnancy-have already been discussed, and in every case of suspected appendicitis in pregnancy the urine should be carefully examined with the microscope for pus corpuscles. The pains, again, may be referred to the abdomen when the real mischief is in the chest. Indeed, the diagnosis of appendicitis in a pregnant woman is beset with all the difficulties that occur in non-pregnant cases, together with others peculiar to pregnancy. Assuming, however, that the dificulties of diagnosis can be overcome by experience the questions which arise are: Does pregnancy predispose. to appendicitis when there has been no previous attack? Does pregnancy in a patient who has formerly had appendicitis without operation render her particularly liable to another attack during or after the pregnancy? Does the coincidence of pregnancy with appendicitis make the latter more severe than it is in average cases? Does appendicitis in the mother render the pregnancy more liable to terminate prematurely and does it militate against the life of the child if the attack occurs when the latter is of viable age? Should the treatment of the appendicitis be precisely similar to that of corresponding attacks in non-pregnant persons, or should the physician's advice be more in the direction of inviting surgical assistance sooner, or more in that of continuing expectant treatment as long as possible in these cases? Should obstetric aid for artificially terminating the pregnancy be sought in any of these cases? These are very vital questions and yet it is by no means easy to answer them. It may be urged tbat no definite rules can be laid down and that the action to be taken in each instance that arises must be decided entirely npon the merits of the particular case. This is true to a considerable extent but when it is borne in mind that very different interpre tations are put upon these "merits of the case" by different observers, even in cases of appendicitis in non-pregnant persons, it becomes evident that it is still more difficult to decide what is best to be done in cases that are at the same time pregnant.

In answer to the first of the above questions it would seem that pregnancy does not predispose to a primary attack of appendicitis. Amongst all the patients that have been in Guy's Hospital suffering from appendicitis during the last 27 years only one was at the same time pregnant. She was a woman, aged 24 years, who had had no former attack, who had had no previous child, and who was six and a half months pregnant when she was suddenly seized with acute appendicitis of moderate severity. The trouble was localised from the first with the usual fulness in the right iliac fossa. Premature labour came on spontaneously a day or two afterwards and the appendicular trouble rapidly resolved without operation.

The second question receives the following answer from Mr. Heaton: "If a patient have previously suffered from the complaint and afterwards becomes pregnant, the pregnancy may light up another attack. This it probably does by stretching or breaking down old inflammatory adhesions as the uterus enlarges and rises out of the pelvis.

On careful questioning it will often be found that there have been one, or several, previcus attacks, though in some cases they have been of so mild a character as to have been almost disregarded. ...... Some surgeons would in every case remove the appendix in women immediately after an attack of appendicitis, if they be of a child.bearing age." It is manifestly of the greatest importance to have a clear answer to the guestion and to know whether the above views are correct or not. A young woman might contemplate marriage and, having had one attack of appendicitis when she was a girl and having recovered from it without operation and having had no symptoms of it since, she might ask the advice of a physician as to whether she ought to have her vermiform appendix removed before her marriage or not. She might be loth to undergo the operation and yet willing to follow the advice that might be given. Ought the operation to be advised in such a case or not? The answer can only be given when the results in a large number of such cases in whom no operation has been done have been collected and analysed. I have attempted to follow a number of hospital cases in this way, but to be of value the statistics obtained in a similar way by many different individuals should be put side by side and compared; the resuits found so far seem to indicate that there is no particular liability for pregnancy to light up fresh appendicular trouble in cases where the former attack occurred years before and appeared to resolve completely. The fact that a girl with ordinary appendicitis may some day become pregnant and might then have a recurrence of the trouble, may doubtless be an additional argument in favour of appendicectomy during convalescence from the attack, but if a patient has not had that operation at the time and has had no return of the symptoms since, the chances of her developing fresh appendicitis later when she becomes pregnant seem to be sufficiently small to warrant the advice that she needs no operation previously to marriage. If, on the other hand, a woman has her first attack of ordinary appendicitis after marriage, at a time when she is not pregnant, and the question arises as to whether she should have her vermiform appendix removed when the acute phase of the attack has passed, the fact that she might become pregnant very soon would seem to be a very real ground for advising that the operation should be done. Although there seem to be practically no statistics upon the subject, pregnancy arising within a few months of an attack of appendicitis would be very liable, one would think, to stretch and break down the immature adhesions in the way that $\mathrm{Mr}$. Heaton describes, and lead to a recurrence of the trouble at a time when it would be particularly unfortunate. For the same reason it would be unwise for a young woman who had had appendicitis, not years ago but within the last few months, to get married; and such a patient would probably be advised to have appendicectomy performed, even though for a similar state of affairs in a man the operation might not be essential.

The answer to the third question-namely, whether or not 
the co-existence of pregnancy makes an attack of appendicitis more severe than the average-cannot be given until, by some process of collective inquiry, all the milder as well as the more severe cases can be collected. This is not at present possible, for the more striking cases become published, the simpler remaining in the background. The proportion of mild to severe cases is thus lost sight of ; consequently the severity of appendicitis during pregnancy is very apt to become exaggerated. Nevertheless, those who have seen cases give it as their personal opinion that pregnancy is a complication which greatly increases the risks and dangers of the disease. The attack may occur at any stage of the pregnancy, as early as the sixth week and as late as the eighth month. The illness may be of all degrees of severity, from transient appendicular colic to the acute fulminating appendicitis which proves fatal in a few hours. In mild attacks, during the early months of pregnancy, the inflammation may completely subside and pregnancy go on uninterruptedly to term. "Owing, however, to the increased blood-supply and to the congestion of the parts due to pressure of the enlarging uterus," cases of appendicitis in pregnancy seem to run an unusually rapid course. Though some subside the majority, if left, seem to go on to suppura. tion and the further advanced the pregnancy the more likely this seems to be.

The danger to the mother's life does not cease with the opening of the abscess, for even after drainage of the cavity in the later stages of pregnancy, or in cases where miscarriage has taken place already, a septic salpingitis or endometritis may be set up with a further liability of extension to the peritoneal cavity. As regards the effects upon the foetus, the latter was born dead in 90 per cent. of the cases collected by Abrahams. ${ }^{12}$ When pus forms in the later months of pregnancy miscarriage almost invariably takes place whether operation be performed or not. Even in cases where no pus is proved to have been present miscarriage or premature labour is more common than is the rule in healthy cases. It is not surprising that an untoward ending of the pregnancy is so frequent when one considers that the enlarged uterus is almost certain to be in contact with the inflamed tissues and to form one wall of the abscess cavity when pus is present.

The answer to the question of whether or not the treatment should be different to that of appendicitis in nonpregnant cases seems to be this: That, upon the whole, operative measures should be accelerated rather than postponed in these pregnancy cases. There are, of course, quite mild cases in which it is better to do nothing active; but in cases of the next degree of severity, where if the patient were not pregnant it might be thought best to wait, the opinion seems to be that operation should be advised on the very ground that the patient is pregnant, particularly in the later months of pregnancy. Doubtless this will not be the opinion of all, ${ }^{13}$ but the reasons given for it seem sound; in the first place, owing to the vascularity of the parts, pus is even more likely to occur in these cases than it is in others ; in the second place, the prospect as regards the child is so poor in any case that the course followed should be almost exclusively that which is in the greatest interests of the mother; and in the third place, the emptying of the uteru by spontaneous miscarriage or premature labour is so likely to occur and with it a rending open of a previously localised inflammation, with consequent spread to the general peritoneal cavity, that it is very dangerous to wait.

The foregoing argument gives the answer to the last of the questions that were put above. It is in the last degree undesirable that obstetric measures for terminating the pregnancy artificially should be resorted to for fear of breaking down adhesions that are helping to localise the inflammation.

Pinard ${ }^{11}$ has collected 45 cases of appendicitis complicating pregnancy, the diagnosis being confirmed in 30 by operation or post-mortem examination. He concludes that appendicitis may attack a pregnant woman at the beginning or at any time during pregnancy; that in the majority of cases it causes abortion, the reason for which is that the

\section{American Journal of Obstetries, February, 1897}

13 See also Vinay : Lyon Médical, Jan. 2nd, 1898. Bouillier : Thèse de Lyon, 1897, and Epitome, Brit. Med. Jour., No. 442, 1898. Toupet and le Filliatre: Bulletin de la Société Anatomique de Paris, December, 1898. THE LANCET, Oct. 11th, 1902, p. 1004. Donoghue: Boston Medical and Surgical Journal, Sept. 4th, 1902 . Mixter : Ibid., Record, 1907, vol. i., p 880

if Semaine Médicale, March 23rd, 1898 fotus becomes infected with the bacillus coli commanis, this organism being recoverable from its blood; that:every type of appendicitis may occur, the severer cases predominating ; and that operation should be advised as early as possible, both for the mother's sake and with a view to diminishing the chances of fatal infection of the child by the bacillus coli communis.

If a pregnant woman develops an attack of appendicitis that is in any degree severe the statistics that are available all indicate that the best chance of saving both the mother and the child is by early operation.

\section{THE SCHOOL AND ITS PART IN THE PREVHNTION OF TUBERCULOSIS. ${ }^{1}$}

\section{BY JOH N HAY, M.D. VICT., M.R.C.P. LOND., ASSISTANT PHYSICIAN TO THE ROYAL INEIRMARY,} LIVERPOOL.

THE subject which I have been asked to discuss with you this afternoon is "The School and its Part in the Prevention of Tuberculosis." The recent legislation dealing with school inspection makes this an opportune moment for carefully reconsidering the many sides to this question and the views which have been expressed by those who have taken an interest in it. I will attempt to place before you some facts bearing on tuberculosis in its relation to the schools and then formulate certain broad lines along which advance seems desirable.

In the last nine or ten years this fight has been actively waged and at last we begin to see undoubted results from our labours. Surely it is a matter of great encouragement that there are those speaking in authority who firmly believe that after another half century of effort tuberculosis will have ceased to be the powerful enemy that it now is. This happy issue, however, can only be attained by unceasing vigilance and continuous effort. One fact alone is sufficient to show what a deadly pest we have in the tubercle bacillus-namely, that one-half of those who die between the ages of 25 and 35 years die from tuberculosis. It is worthy of note that during the last 30 years the death-rate from consumption in Fingland has fallen from 21 to 12 per 10,000 of the population. ${ }^{2}$ This grand advance means an enormous saving of human life. But what a different tale your own country tells. 30 years ago your death.rate from consumption was only 18 per 10,000 ; now it is 22 . These figures "give us pause" and are in themselves sufficient to give rise to much searching of heart among those responsible for the guidance of the people in matters of public health. There is no reason why a definite and rapid improvement should not take place in Ireland. What is needed is coördination of the many agencies already in existence, a wider knowledge of the nature of tuberculosis and the means of stamping it out, and last, and of extreme importance, enthusiasm and money. "Money is absolutely essential in this fight. Gvery medical man knows well when pondering on the outlook of a patient suffering from pulmonary tuberculosis that the chances of cure, other things being equal, depend on the financial status of the sufferer. The same holds good with a nation. The more money it can afford to put down the better chance there is of a speedy and permanent diminution of the amount of tuberculous disease in the conntry.

Professor Koch in his Nobel lecture ${ }^{3}$ said that he considered "notification, hospitals, sanatoriums, and carestations the heavy artillery in the battle against tuberculosis," and he says further: "But there are lighter weapons, too, which cannot themselves exercise so incisive an effect but the coöperative help of which we cannot dis. pense with." Among these he reckons "in the first place, all efforts to instruct the people as to the danger of tuberculosis and to keep awake the interest of the masses in the combating of tuberculosis by popular publications, lectures, exhibitions, and other means."

To-day we are to discuss more particularly the schools and their relation to the prevention of tuberculosis and $I$ venture to think that Professor Koch would have classed the schools as one of the more powerful of the lighter weapons of which. 1908

A paper read at the Tuberculosis Exhibition in Cork on Jan. 4th 2 Brit. Med. Jour., 1906, vol. i., p. 1556. 3 THE LANCET, May 26th, 1906 , p. 1449. 